\title{
OS 15 ANOS DO CURSO DE ENGENHARIA CIVIL DA UNIVERSIDADE ESTADUAL VALE DO ACARAÚ-UVA
}

Juscelino Chaves Sales - juscelinochaves@hotmail.com*

Universidade Estadual Vale do Acaraú, Departamento de Engenharia Civil*

Rua Socorro Azevedo, 150, bl-01, apt-203*

60810-400-Fortaleza-Ceará*

Resumo: O primeiro curso que se tem notícia foi o de Engenharia Militar onde se formavam engenheiros devido a necessidade de se construir equipamentos e planejamento para guerras. Sabemos que a engenharia civil pode ser considerada como a primeira de todas as engenharias que temos hoje. No Brasil A Real Academia de Artilharia, Fortificação e Desenho ou Escola Politécnica (Poli) seria o primeiro curso de Engenharia Civil enquanto no Ceará o curso de engenharia civil da UFC localizada em Fortaleza foi o primeiro a ser instalado e já completou 60 anos de existência. O presente trabalho mostra o curso de Engenharia Civil da Universidade Estadual Vale do Acaraú - UVA sediado em Sobral no interior do Ceará em seus 15 anos de existência. Até a metade do ano de 2012 o curso de Engenharia Civil da UVA já tinha formado 188 engenheiros civis. Constatou-se que o curso é um dos mais concorridos da Universidade Estadual Vale do Acaraú e vem formando excelentes engenheiros civis para trabalhar na indústria da construção civil e nas universidades como pesquisadores, ao longo dos anos de sua existência.

Palavras-chave: Engenharia Civil. UVA. Ex-alunos.

\section{INTRODUÇÃO}

O Coreia do Sul investe hoje 3\% do PIB em educação já o Brasil investe somente $1 \%$ do PIB, onde hoje também a China faz um investimento pesado em ciência e tecnologia (DAVILA, 2019).

A Coreia do Sul é um dos países do que mais tem engenheiros em relação a quantidade de formandos em outras profissões. Também podemos dizer que no começo dos anos 60 a Coreia do Sul tinha um IDH (Índice de Desenvolvimento Humano) pior que o do Brasil e partir da década de 60 o pais asiático investiu pesado em educação e incentivou seus jovens a se voltarem para a área das ciências exatas onde temos o curso de engenharia civil. Hoje grandes empresas na área de tecnologia são coreanas com a Samsung, LG etc.

O Brasil forma poucos engenheiros levando em consideração a quantidade de formandos nas outras profissões. O estado de Santa Catarina é hoje o estado que tem a maior quantidade de engenheiros por habitantes, tendo como consequência o seu IDH (Índice de Desenvolvimento Humano) só ser menor que o do estado de São Paulo que é a força (motor) da economia brasileira. O estado com maior IDH do Brasil que é o estado de São Paulo, é onde se encontra a maior quantidade de cursos de engenharia civil. 
A necessidade do curso de engenharia civil na região norte do estado decorreu, de uma demanda maior de engenheiros civis na região norte, pois Sobral que é a cidade onde o curso está instalado é a quarta economia do Estado do Ceará.

A oferta de cursos de graduação de Engenharia Civil no país é razoável. Isto ocorre, devido à grande tradição e importância do curso de Engenharia Civil que historicamente foi um dos primeiros cursos de engenharia a surgir e devido ao desenvolvimento socioeconômico do país nas últimas duas décadas.

Devido ao grande desenvolvimento socioeconômico que a região Norte do Estado do Ceará vem atravessando foi de fundamental importância a criação do curso de Engenharia Civil, na Universidade Estadual Vale do Acaraú.

O presente trabalho tem como objetivo mostrar a importância e a história do curso de Engenharia Civil da UVA durante os seus 15 anos de existência e onde andam os seus exalunos.

\section{METODOLOGIA}

O presente trabalho foi feito através de pesquisa bibliográfica em jornal, sites, artigos etc. Também foi feita uma consulta ao projeto pedagógico do curso de bacharelado em engenharia civil da UVA e contato com ex-alunos.

\section{O CURSO DE ENGENHARIA CIVIL DA UVA}

A Universidade Estadual Vale do Acaraú (UVA) está localizada na cidade de Sobral que possui hoje mais de 200 mil habitantes e fica na zona norte do estado do Ceará na região nordeste do Brasil.

O curso de bacharelado em Engenharia Civil da Universidade Estadual Vale do Acaraú abrange sobre a sua influência uma grande área geográfica com mais de 50 municípios e uma população de 1,5 milhões de habitantes. A UVA vem formando engenheiros desde o ano de 2009 (PPC, 2016).

A justificativa para a existência do curso de engenharia civil da UVA levou uma série de fatores como déficit habitacional na região, o investimento feito em infraestrutura no estado do Ceará como a construção do porto do Pecém, pavimentação de estradas etc. Também investimentos em saneamento básico e a própria necessidade de se fazer pesquisas científicas voltadas para resolver os problemas inerentes a região norte do Estado do Ceará.

O curso de engenharia civil começou através de uma parceria entre a Universidade Estadual Vale do Acaraú, a prefeitura de Sobral e a Diocese de Sobral. O prefeito de Sobral era na época o engenheiro civil Cid Gomes e o bispo de Sobral era Dom Aldo Pagoto. O professor que tomou a frente para que o curso fosse aberto foi o professor Francisco Carvalho Arruda Coelho que era professor efetivo do curso de Tecnologia da Construção Civil. Quando o curso começou foi feita uma parceria com a Universidade Federal do Ceará, onde o professor Dr. Alexandre Araújo Bertini da UFC passou a dar aulas no curso da UVA por um determinado tempo, que foi até a formação da primeira turma.

Um ponto importante para o início do curso de engenharia civil foram as instalações já existentes do curso de Tecnologia da Construção Civil como os laboratórios e as edificações como salas de aula, auditório banheiros etc. Além disso, as disciplinas do ciclo básico deste curso são na sua maioria disciplinas já oferecidas pelas Coordenações dos Cursos de Matemática, Física, Química e Ciências da Computação, onde os professores desses cursos lecionam até hoje no curso de engenhara civil. Algumas disciplinas do ciclo profissional nos anos inácias do curso de engenharia civil foram ministradas por professores do Curso 
de Tecnologia da Construção Civil. O primeiro coordenador do curso de engenharia civil era do curso de Tecnologia da Construção Civil que foi o professor Dr. Francisco Carvalho como também outros dois coordenadores do curso também foram professores do curso de Tecnologia da Construção Civil que foram os professores Caio Sander e Joseli Dantas.

O primeiro professor concursado do curso que é professor Juscelino Chaves Sales na UVA já desempenhou a função de vice coordenador e coordenador do curso de Engenharia Civil, mesmo sendo engenheiro mecânico porem é mestre em Engenharia e Ciências do Materiais.

A necessidade de profissionais qualificados pela indústria da construção civil, fato hoje notório, remete à necessidade da formação de profissionais de engenharia civil em nível de graduação. A formação de engenheiros civis na UVA está em sintonia com o desenvolvimento das iniciativas de qualidade e produtividade no setor da construção civil do estado do Ceará.

Apesar da oferta de cursos de Engenharia Civil no país ser razoável, a situação no estado do Ceará é bastante diferente. Até o ano de 2014, no estado do Ceará, o curso de Engenharia Civil era oferecido em Fortaleza somente pela Universidade Federal do Ceará - UFC e Universidade de Fortaleza - UNIFOR, em Juazeiro do Norte pela Universidade Federal do Ceará - UFC. Depois de 2014 o Ministério da Educação autorizou o início de dois novos cursos de Engenharia Civil em Fortaleza, um no Instituto Federal de Educação, Ciência e Tecnologia do Ceará - IFCE, e o outro no Centro Universitário UNICRISTUS. Outro curso de Engenharia Civil que foi instalado no município de Crateús pela Universidade Federal do Ceará- UFC. O interior do estado do Ceará não possuía, até a implantação do Curso da UVA, nenhum curso de Engenharia Civil. Recentemente foram abertos outros cursos no estado do Ceará e só em Sobral já temos três cursos um em uma universidade pública que é o da UVA e os outros dois em faculdades particulares como a Faculdade Luciano Feijão e a UNIINTA.

Existem hoje cerca 18 cursos de engenharia civil no estado do Ceará sendo três em Sobral. Hoje temos também instalados o curso de engenharia civil em Russas pela Universidade Federal do Ceará - UFC e o curso de engenharia civil da UNICATÓLICA na cidade de Quixadá.

Um dos mais importantes aspectos que justifica a criação do curso de graduação em Engenharia Civil é o grande déficit habitacional do país, por ser o Engenheiro Civil o profissional que precisa de mais tempo de formação intelectual da indústria da construção civil. Outro fator importante foi o aquecimento da economia nos últimos anos e a instalação do Plano de Aceleração do Crescimento (PAC), que foi um projeto do Governo Federal. Porem nos últimos seis anos o país entrou em uma crise econômica diminuindo os investimentos em infraestrutura, que afetou sensivelmente as obras de construção civil.

O processo de industrialização recente do nordeste brasileiro, e particularmente do estado do Ceará, que vem recebendo investimentos diretos nos últimos anos, considerando-se a existência do Porto do Pecém, aponta de forma inequívoca para a expansão do mercado de trabalho na indústria da construção existente, claro que a pandemia do coronavirus vai afetar sensivelmente o setor da construção civil e não estava na previsão do governo do estado do Ceará.

Nos últimos anos o Complexo Industrial e Portuário do Pecém - CIPP vem precisando de mão de obra principalmente de engenheiros civis, pois já estão perto de construir uma termoelétrica, onde já existem alunos egressos da Universidade Estadual Vale do Acaraú trabalhando no local. No ano de 2012, iniciou a construção da CSP (Companhia Siderúrgica do Pecém), inclusive estava em andamento à cravação das estacas (fundações) da obra. Também serão necessários engenheiros civis para a construção de uma futura Refinaria que será instalada próximo ao Porto do Pecém. Vale ressaltar que a construção da Companhia Siderúrgica do Pecém (CSP) teve como consequência a construção de um polo metal mecânico onde eram necessários mais engenheiros civis, para construir essas indústrias. A cerca de nove anos atrás a Universidade Estadual Vale do Acaraú-UVA, participou ativamente, nas discussões juntos 
com as universidades e outras instituições de ensino do Ceará de como suprir a demanda por novos engenheiros civis para do CIPP (Complexo Industrial e Portuário do Pecém). Alguns exalunos da UVA já trabalharam no CIPP.

Entre os projetos considerados estruturantes para a economia cearense, aquele que, de fato, avançou ao longo do ano de 2012 foi a Companhia Siderúrgica do Pecém (CSP). Somente a empresa responsável pelas obras da CSP, previa contratar oito mil pessoas. O empreendimento é o primeiro e único a estar inserido na região da ZPE. O ano de 2012 também garantiu a atração de um novo projeto siderúrgico para o Ceará, a Siderúrgica Latino-Americana (Silat), uma laminadora, instalada também no Complexo Industrial e Portuário do Pecém (CIPP) (Jornal Diário do Nordeste, 2012).

No ano de 2013 houve a necessidade da contratação de engenheiros civis. Inclusive uma empresa de consultoria que contratava engenheiros civis para a s construtoras, chegou a entrar em contato com o coordenador do curso de engenharia civil precisando contratar engenheiros civis, pedindo assim a indicação desses engenheiros ao coordenador, pois estava havendo uma escassez de profissionais na área.

Outra necessidade de engenheiros civis na região será a construção do Cinturão das Águas, onde será necessária a construção de canais para trazer água dos rios São Francisco e Tocantins, como também a construção da Barragem Fronteiras que já está sendo construída no município de Crateús, com capacidade de mais de 500 milhões de metros cúbicos de água, que são os equipamentos importantes para amenizar o problema hídrico da região norte do estado do Ceará.

Nos anos de 2012 e 2013 a UVA formou em média 60 engenheiros civis por ano, daí vem a grande importância do curso de Engenharia civil para região, valendo citar a existência de alunos de outras regiões do estado do Ceará como também do estado do Piaui.

No ano de 2012 uma empresa de consultoria ligava para o coordenador do curso procurando contratar engenheiros recém-formados pois existia uma escassez de engenheiro no mercado já por volta de 2015 os alunos e que procuravam o ex-coordenador do curso atrás de arranjar emprego.

O curso de Engenharia Civil da UVA vem contribuindo para a redução do déficit habitacional formando profissionais de alta competência necessários para a indústria da construção civil como também para a academia.

Em Sobral existem várias indústrias de base para a indústria da construção civil é a indústria de cimento do Grupo Votorantim é um exemplo pois produz a mais de 50 anos cimento Portland para poda a região norte do Estado do Ceará. Também temos é possível encontrar na região as indústrias de cerâmica, de fabricação de postes de concreto, de mineração (ferro, granito e outros) etc., são também grandes as oportunidades de emprego para o profissional da Engenharia Civil. Existe também uma demanda para processo de infraestrutura, especialmente no setor de habitação e saneamento.

Dado o exposto acima se pode afirmar que o estado do Ceará, não somente Fortaleza, mas também o interior possui, em termos relativos, um grande déficit habitacional. O curso de Engenharia Civil da UVA vem contribuindo para a redução deste déficit diplomando profissionais de alta competência necessários para a indústria da construção civil.

Durante o primeiro semestre do Ano de 2014 existiam 476 alunos matriculados. No primeiro semestre de 2013 colaram grau 23 alunos e no segundo semestre 38, ou seja, em 2013 colaram grau 61 alunos. No segundo semestre de 2012 colaram grau 38 alunos.

A UVA só possui um curso de engenharia que é o de engenharia civil, enquanto na UFC no Centro de Tecnologia existem 13 cursos de graduação em engenharia e 9 cursos de pôs graduação. O programa 
de pós graduação em Recursos Hídricos possui nota máxima 7, e existem dois programas com nota 6 que é o de Engenharia de Teleinformática e de Engenharia Química.

Desde o ano de 2003, a UVA promove, juntamente com Instituto de Estudos dos Materiais de Construção (IEMAC), um dos mais importantes fóruns de Engenharia da América Latina: o Congresso Internacional sobre Patologia e Reabilitação de Estruturas (CINPAR). Em 2011, o Congresso aconteceu em Fortaleza, no período de 1 a 4 de junho, e contou com palestrantes de 12 países (SINIBALDI, 2011).

O crescimento do número de candidatos para o curso até o ano de 2011, pode ser explicado pelo desenvolvimento econômico do país e pela necessidade de profissionais. Houve um crescimento econômico muito grande durante o Governo da época, o que ocasionou uma demanda maior por engenheiros. As obras na região Norte do Estado do Ceará também aumentaram as possibilidades de emprego.

Em 2011, o curso de Engenharia Civil e Ambiental da Universidade Estadual Vale do Acaraú alcançou a maior concorrência entre todos os cursos de Engenharia Civil ofertados no Estado, com uma média anual de 13,46 candidatos por vaga. O número ultrapassa a concorrência divulgada pelo Sistema de Seleção Unificada (SISU) do curso de Engenharia Civil da Universidade Federal do Ceará (UFC), que atingiu a marca de 12,69 candidatos por vaga (SINIBALDI, 2011).

Para ser universidade de acordo com Conselho Nacional de Educação (desde 2010) a universidade tem que ter no mínimo 2 (dois) cursos de doutorado e 4 (quatro) de mestrado, como também um terço dos professores ter dedicação integral (exclusiva) e realizar pesquisa ensino e extensão (FERRASOLI, 2018).

O curso começou com o nome de curso de Engenharia Civil e Ambiental, porem hoje o nome passou a se chamar somente curso de engenharia civil. O título do curso anterior era justificado porque os alunos eram formados e existia duas ênfases que ele podia colar grau que eram a ênfase da construção civil e a ênfase ambiental. Percebeu-se ao longo dos anos que a grande maioria dos alunos cursavam como prioridade a ênfase da construção civil. Existiam quatros disciplina obrigatórias na ênfase ambiental e quatro na construção civil que o aluno tinha que optar. Nem todos os alunos cursavam as duas ênfases pois era necessário adiar a colação de grau por mais seis meses.

No ano de 2012 de acordo com a classificação das universidades brasileiras pela RUF (Ranking Universitário da Folha), o curso de engenharia civil da UVA ficou em primeiro lugar no item ensino de todos os cursos de engenharia civil do estado do Ceará passando até a Universidade Federal do Ceará.

A metodologia de ensino utilizada no curso de engenharia civil da UVA articula a teoria com a prática e estimula o raciocínio logico, crítico e contextual. A concepção de ensinoaprendizagem adotada respalda na interação entre os participantes do curso- entre professoraluno e aluno-aluno. Entende-se que o processo de ensino-aprendizagem requer por parte do docente além do domínio do saber historicamente acumulado em sua área o desenvolvimento de um conjunto de habilidades e competências (PPC, 2016).

Durante os seus 15 anos de funcionamento o curso de engenharia civil da UVA teve cinco coordenadores que foram os professores, Francisco Carvalho, Jocely Dantas, Caio Sander, Juscelino Chaves e Eder Paulus que é o atual coordenador.

\section{ONDE ESTÃO OS EX-ALUNOS HOJE?}


A atual professora Kelvya Moreira de Vasconcelos Oliveira do curso de engenharia civil da UVA, é ex-aluna tanto do curso de Tecnologia da Construção Civil e do curso de engenharia civil da Universidade Estadual Vale do Acaraú-UVA.

O ex-aluno Francisco da Silva Brandão do curso de engenharia civil da UVA, esteve na Itália onde estudou na Universidade Politécnica de Turim pelo programa Ciência sem Fronteiras e quando voltou foi recebido no aeroporto pelo professor Juscelino Chaves Sales e sua mãe dona Francisca Brandão. Hoje o ex-aluno está fazendo mestrado na área de estruturas na Universidade Federal do Rio Grande do Sul.

A universidade vem estimulando seus alunos e professores a participarem de eventos relacionados à engenharia civil e áreas afins. O principal objetivo dos seminários, congressos etc.; é contribuir para a formação de engenheiros civis atualizados quanto ao mercado de trabalho e que possam trazer benefícios à sociedade.

Alguns alunos do curso de engenharia civil da UVA participaram do programa Ciência sem Fronteiras, onde um deles foi para a Itália onde estudou na Universidade Politécnica de Turim e chegou a publicar um artigo juntamente com as professores da UVA e da universidade italiana em um congresso no Brasil o CONTEC no ano de 2015, que foi realizado em Fortaleza no estado do Ceará no Brasil. O aluno quando voltou da Itália foi recebido no aeroporto pelo professor que foi seu orientador da UVA. Pelo programa Ciência sem Fronteiras outros alunos foram para EUA, Irlanda, Grã-Bretanha etc.

Uma aluna recentemente foi selecionada para fazer o mestrado no ITA. Existem alunos fazendo mestrado e doutorado em diversas universidades do Brasil como a UNISINOS, UFRGS, UNB, PUC-RIO, UFU etc.

Os alunos que entram na universidade vêm de toda a região norte do estado do Ceará, porem também já passaram pelo curso alunos de outras cidades do interior do estado do Ceará como da cidade de Palhano e da capital Fortaleza. Também vem alunos do Piauí estudar na UVA, como da cidade de Parnaíba, São Raimundo Nonato, Cocal da Estação etc. A Figura 1 mostra uma placa de formatura onde os engenheiros formados colocaram na placa as cidades de onde eles vieram. Podemos perceber também pela Figura 1 que da cidade de Sobral onde a universidade está instalada só tem três alunos de 20 alunos que concluíram o curso. As cidades contempladas na placa são: Morrinhos, Carnaubal, Frecheirinha, Senador Sá, Itapipoca, Moraújo, Camocim, Monsenhor Tabosa, Viçosa do Ceará, Tianguá, Massapê, Crateús.

Figura 1 - Placa de formatura com os engenheiros recém formados.

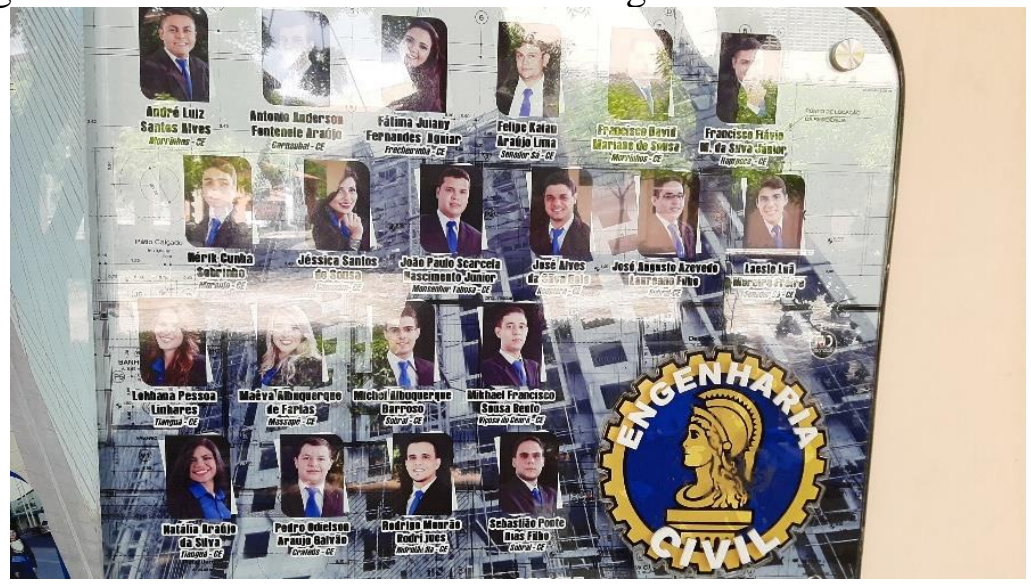

Fonte: Própria, 2019. 
Como ex-alunos temos atualmente dois professores na Universidade Federal do Ceará. Uma ex-aluna é professora do Departamento de Hidráulica e é a vice- coordenadora do curso de engenharia civil que fica localizado no Campus do Pici na cidade de Fortaleza, a professora Dra. Mariana Vela Silveira. Já o outro ex-aluno é o professor Dr. Ezequiel Fernandes Teixeira Mesquita que é o coordenador do curso de engenharia civil do campus de Russas, cidade localizada no interior do Estado do Ceará.

No interior do Estado do Ceará, temos ex-alunas professoras do IFCE (Instituto Federal do Ceará) e do curso de engenharia civil da Universidade Federal do Ceará na cidade de Crateús.

Vários alunos montaram construtoras, ou seja, hoje são empresários da indústria da construção civil, e outros profissionais são concursados em órgãos públicos como engenheiros e outros estão empregados como responsáveis técnicos em construtoras.

Outros alunos fizeram mestrado e são professores de faculdades particulares tanto na cidade de Fortaleza, com na cidade de Sobral, como a Faculdade Ari de Sá em Fortaleza, UNINTA e Luciano Feijão em Sobral. Existe um ex-aluno que é professor de uma faculdade particular na cidade Porto Alegre no Rio Grande do Sul.

\section{CONCLUSÕES}

A graduação em Engenharia Civil da UVA já contribuiu para a formação de profissionais de excelente qualidade e hoje os seus ex-alunos estão ocupando o mercado de trabalho como donos de construtoras, trabalhando em empreiteiras, como engenheiros na construção de edifícios e também na área acadêmica pois alguns ex-alunos já são professores universitários tendo concluído mestrado e doutorado. Já dois ex-alunos são professores adjuntos da Universidade Federal do Ceará. Percebeu-se que o governo do estado do Ceará não está investindo nas suas universidades acarretando problemas no curso de bacharelado em engenharia civil da UVA, como a falta de contratação de professores efetivos e a falta de laboratórios, dificultando cada vez a pesquisa científica, o ensino, a extensão e a inovação. Mesmo com as dificuldades financeiras o curso de engenharia civil da UVA vem formando excelentes profissionais para o mercado de trabalho.

\section{REFERÊNCIAS}

DAVILA, R., Entrevista com Denise Pires de Carvalho reitora da UFRJ, Globo News, abr. 2019.

FERRASOLI, Dante., GAMBA, Estêvão., RIGHETTI, Sabine. Uma em cada três universidades no Brasil não pode ser considerada como tal pela lei. Disponível em: <http://ruf.folha.uol.com.br/noticias/2018/10/1982673-uma-em-cada-tres-universidades-nobrasil-nao-pode-ser-considerada-como-tal-pela-lei.shtml>. Acesso em: 01 out. 2018.

JORNAL DIÁRIO DO NORDESTE, 2012. CSP foi a obra estruturante que obteve avanços. Disponível em: <https://diariodonordeste.verdesmares.com.br/editorias/negocios/csp-foi-aobra-estruturante-que-obteve-avancos-1.45828>. Acesso em: 28 mai. 2020.

PPC. Projeto Pedagógico do Curso de Graduação em Engenharia Civil. Universidade Estadual Vale do Acaraú. 2016. Sobral. 
RUF, 2018. Disponível em: <http://ruf.folha.uol.com.br/2018/ranking-de-cursos/engenhariacivil/> Acesso em: 01 out. 2018.

SINIBALDI, S. V., Curso de Engenharia Civil da UVA é o mais concorrido do Ceará em 2011. Disponível em: < https://www.ceara.gov.br/2011/07/07/curso-de-engenharia-civil-dauva-e-o-mais-concorrido-do-ceara-em-2011/>. Acesso em: 23 abr. 2019.

\section{THE 15 YEARS OF THE CIVIL ENGINEERING COURSE OF THE VALE DO ACARAÚ STATE UNIVERSITY - UVA}

Abstract: The first known course was that of Military Engineering where engineers were trained due to the need to build equipment and planning for wars. We know that civil engineering can be considered as the first the engineering we have today. In Brazil The Royal Academy of Artillery, Fortification and Design or Polytechnic School (Poli) would be the first Civil Engineering course while in Ceará the UFC civil engineering course located in Fortaleza was the first to be installed and has already completed 60 years of existence. The present work shows the Civil Engineering course of the State University Vale do Acaraú - UVA based in Sobral in the interior of Ceará in its 15 years of existence. By the middle of 2012, the Civil Engineering course at UVA had already trained 188 civil engineers. It was found that the course is one of the most popular at the Universidade Estadual Vale do Acaraú and has been training excellent civil engineers to work in the construction industry and in universities as researchers over the years of its existence.

Keywords: Civil Engineering. UVA. Ex-students. 